\title{
Silviano Santiago e o discurso transgressor latino-americano: balbucios a partir da Fronteira-Sul ${ }^{1}$
}

\author{
Silviano Santiago y el discurso transgresor latinoamericano: balbuceos a \\ partir de la Frontera Sur
}

\author{
Silviano Santiago and the Latin American transgressive discourse: \\ babbling from the Southern Border
}

\author{
Dênis Angelo Ferraz ${ }^{2}$ \\ Edgar Cézar Nolasco ${ }^{3}$
}

\begin{abstract}
Resumo
Com esta reflexão que se erige como balbucio teórico (ACHUGAR, 2006), objetiva-se evidenciar uma leitura crítico-biográfica fronteiriça, a partir do discurso transgressor que é evocado pelo escritor mineiro, Silviano Santiago, sobretudo em sua conceituação do entre-lugar do discurso latino-americano, que aponta para uma abertura ao debate pós-colonial podendo se relacionar com a desobediência epistêmica de Walter Mignolo, esse discurso se erige a partir da cultura marginal e dos corpos que acabam por se tornarem inconvenientes (SANTIAGO, 2019) frente às normas instituídas socialmente. A partir de tais indícios é possível vislumbrar toda relevância de se erigir tal reflexão, engendrando nesse debate conceitual um pensamento outro, numa abordagem que se pauta a partir de estudos descoloniais, que leve em conta o bios e o lócus de onde se emerge esses discursos, incorporando assim o pensamento que emerge na e a partir da fronteira e meu próprio bios, minha condição de pesquisador e homem negro. Depreendendo-se à uma reflexão que se paute na desobediência epistêmica (MIGNOLO), por meio de uma discussão à luz das conceituações de Edgar Cézar Nolasco, Boaventura Santos e de Walter Mignolo. Com esse intento evidencia-se a importância de erigir leituras com base no pensamento fronteiriço, pois é nítido que a partir das inconveniências de corpos transgressores emergem vozes dissonantes como resistências políticas (SANTIAGO, 2019) em busca de (re)existirem, de modo que reforçam a urgência de se aprender a desaprender para assim reaprender de um modo outro.
\end{abstract}

Palavras-Chave: corpo; crítica biográfica-fronteiriça; descolonialidade; desobediência epistêmica; Silviano Santiago.

Resumen

Con este reflejo erigido como un balbuceo teórico (ACHUGAR, 2006), el objetivo es evidenciar una lectura crítico-biográfico fronteriza, a partir del discurso transgresor que es evocado por el escritor brasileño, Silviano Santiago, sobre todo en su conceptualización del entre-lugar del discurso latinoamericano, que apunta a una apertura al debate poscolonial que puede estar relacionado con la desobediencia epistémica de Walter Mignolo, tal discurso se dirige desde la cultura marginal y desde los cuerpos que acaban resultando inconvenientes (SANTIAGO, 2019) frente a las normas socialmente instituidas. A partir de tal evidencia se vislumbra toda la relevancia de construir tal reflexión, generando en este debate conceptual un pensamiento otro, en un enfoque basado en estudios descoloniales, que toma en cuenta el bios y el locus de donde surgen estos discursos, incorporando así el pensamiento que emerge en y desde la frontera, bien como a mi propio bios, mi condición de investigador y hombre negro. Desde una reflexión basada en la desobediencia epistémica (MIGNOLO), pasando

\footnotetext{
${ }^{1}$ Artigo apresentado no Latinidades - Fórum Latino-Americano de Estudos Fronteiriços, na modalidade online, 2020 .

${ }^{2}$ Bacharel em Ciências Sociais - UFMS; Membro do Núcleo de Estudos Culturais Comparados - NECC; Campo Grande, Mato Grosso do Sul, Brasil; denisferraz_une@hotmail.com

${ }^{3}$ Dr. FAALC; PPGEL. Coordenador do Núcleo de Estudos Culturais Comparados - NECC; Campo Grande,

Mato Grosso do Sul, Brasil; ecnolasco@uol.com.br
} 
por una discusión a la luz de los conceptos de Edgar Cézar Nolasco, Boaventura Santos y Walter Mignolo. Con esta proposición, se evidencia la importancia de erigir lecturas basadas en el pensamiento de frontera, pues es evidente que, de los inconvenientes, de los cuerpos transgresores surgen voces disonantes como resistencias políticas (SANTIAGO, 2019) en busca de (re) existir, para que reforzar la urgencia de aprender a desaprender para volver a aprender de manera otra.

Palabras claves: cuerpo; crítica biográfica-fronteriza; decolonialidad; desobediencia epistémica; Silviano Santiago.

\section{Abstract}

With this reflection that is erected as a theoretical babbling (ACHUGAR, 2006), the objective of showing a border critical-biographical reading, from the transgressive discourse that is evoked by the writer of Minas Gerais, Silviano Santiago, above all in its conceptualization of the between-place of Latin American discourse, which points to an opening to the postcolonial debate that can relate to the Walter Mignolo's epistemic disobedience, this discourse is erected from marginal culture and bodies that eventually become inconvenient (SANTIAGO, 2019) socially established standards. From such indications it is possible to glimpse all the relevance of erecting such reflection, engendering in this conceptual debate another thought, in an approach that is based on decolonial studies, that takes into account the bios and locus from which these discourses emerge, thus incorporating the thought that emerges in and from the border and my own bios, my status as a researcher and a black man. Imprecating a reflection that is based on epistemic disobedience (MIGNOLO), through a discussion in the light of the concepts of Edgar Cézar Nolasco, Boaventura Santos and Walter Mignolo. With this intent, the importance of erecting readings based on frontier thinking is evidenced, because it is clear that from the inconveniences of transgressive bodies emerge dissonar voices as political resistance (SANTIAGO, 2019) in search of (re)exist, so that they reinforce the urgency of learning to unlearn to relearn in another way.

Keywords: body; biographical-border criticism; decoloniality; epistemic disobedience; Silviano Santiago

\section{Introdução}

Pensar a partir da periferia implica pensar a partir dos projetos globais que se cristalizam, de forma hegemônica, na cultura; significa, também, em transculturar tais projetos globais em projetos locais periféricos que façam sentido para a cultura periférica; significa, ainda, e sobretudo, em rearticular os saberes e os discursos todos de uma perspectiva da crítica subalterna. Uma reflexão crítica periférica, por sua natureza de fora do lugar e sua estratégia transdisciplinar, só pode se situar e, por conseguinte, ancorar seu discurso na margem do saber instituído e dos discursos acadêmico e disciplinar, como forma de barrar um pensamento totalizante vindo de fora. (NOLASCO, 2013, p. 87)

Em tempos difíceis como o nosso, sem revolução, mas não sem esperanças, em que o cinismo e ceticismo aparecem como estratégias imobilizadoras disfarçadas de atitudes críticas, ler Silviano Santiago continua sendo uma referência para realizar uma política do fragmento e da diversidade. (LOPES. 2012, p. 29).

Solamente puede ofrecer resistencia política el cuerpo inconveniente. (SANTIAGO. 2019, s/p.)

Ao propor aqui uma reflexão à luz de uma visada descolonial, quero pensar o discurso transgressor dos corpos periféricos/marginalizados, aqueles que tem sido invisibilizados e excluídos historicamente: negros, povos latinos originários, mulheres, homossexuais, campesinos, ou seja, as vítimas deste sistema colonialista eurocêntrico, capitalista, patriarcal, racista, fundamentado numa epstemologia crítica biográfica fronteiriça, na partir do lócus que 
na esteira de Edgar Cezár Nolasco denomino, fronteira-Sul, esse espaço geoistórico e epistemológico de onde emergem reflexões, memórias e paisagens que moldam e configuraram o próprio ser daqueles que ai habitam, esse lugar onde o sol se põe (Nolasco, 2014), local de onde se é e de onde se pensa (Mignolo), onde corpos fronteiriços subalternizados se põe inconvenientemente frente as normas de condutas do pensamento moderno/colonial hegemônico, e de seus propagadores/reprodutores.

O que de tal modo, nos suscita a inserir à discussão, o escritor mineiro Silviano Santiago, partindo da reflexão do papel do intelectual em épocas de autoritarismo, com base em sua ficção Em Liberdade (1981), articulando a tal reflexão a transgressão apresentada pelo discurso latino-americano, do papel do crítico latino-americano, pensando também a partir da realidade de nossos dias como se dá essa reflexão cerca de 40 anos após sua publicação. Junto aqui, engendramos também reflexões trazidas a partir de seu texto intitulado: Inconveniências do corpo como resistência política (2019).

Ao compreendermos como necessário ter em mente que "a produção do conhecimento é inseparável das sensibilidades do local geoistórico e que os locais históricos, no mundo colonial/moderno, foram moldados pela colonialidade do poder" (MIGNOLO. 2003, p. 249), de forma que "o sujeito social pensa, ou produz conhecimento, a partir de sua "história local", ou seja, a partir do modo que "lêe" ou "vive" a "história local" (ACHUGAR, 2006, p. 29), e assim assumimos como condição vital para este intento, adotarmos a opção descolonial, superando o que é tido apenas como balbucio, convicto de que esta opção "não é só uma opção de conhecimento, uma opção acadêmica, um domínio de 'estudo', mas uma opção de vida, de pensar e de fazer" (MIGNOLO, 2017, p. 31).

Podendo dessa forma pautar essa reflexão em nossas escrevivencias superando o modelo hegemônico caracterizado pelo fazer cientifico e a razão moderna/colonial expondo as heranças coloniais que a modernidade/(neo)colonialidade tenta invisibilizar e ignorar, a ferida colonial que ainda jaz aberta e que sangra nos corpos marginalizados e subalternizados, como em nossa reflexão apontamos como corpos fronteiriços. Deixando nítido assim que essa abordagem passa pelo crivo de uma leitura que parte da reflexão da produção de crítica literária e cultural do escritor mineiro Silviano Santiago, ante isso nosso intento se pauta na desobediência epistêmica de Walter Mignolo e busca aprender com o Sul, erigindo uma reflexão pautada num paradigma outro que se mostra como basilar para essa opção assumida.

\section{Desprender-se para sentir e pensar na/a partir da Fronteira-Sul}

Desprender-se significa não aceitar as opções que lhe brindam. Não pode evitá-las, mas ao mesmo tempo não quer obedecer. Habita a 
fronteira, sente na fronteira e pensa na fronteira no processo de desprender-se e resubjetivar-se.

MIGNOLO. 2017, p. 19.

No intento de erigir um pensamento outro, pautando-se numa teorização descolonial, almejo nesta seção suscitar uma reflexão na esteira da citação de Walter Mignolo, que nos impele a desprender-nos para assim ser possível pensar descolonialmente, também de Edgar Nolasco na trilha do teórico argentino complementando-o, ao apontar que ao aprender a se desprender, pode-se livrar-se das amarras do pensamento moderno/colonial. Desse modo vislumbro erigir nessa discussão, desobediente e a partir do local de meu balbucio (Achugar), de onde sou e de onde penso (Mignolo) minha fronteira-Sul.

Esse lugar é o local em que "fui colocado, mas que também escolhi" (ACHUGAR, 2006, p. 14), onde corpos fronteiriços subalternizados se põe inconvenientemente frente as normas de condutas do pensamento moderno/colonial hegemônico, e de seus propagadores/reprodutores. O que me suscita inserir à discussão, o escritor mineiro Silviano Santiago, partindo da reflexão do papel do intelectual em épocas de autoritarismo, com base em sua ficção Em Liberdade (1981), articulando a tal reflexão a transgressão apresentada pelo discurso latino-americano, do papel do crítico latino-americano, buscando pensar também a partir da realidade de nossos dias como se dá essa reflexão cerca de 40 anos após sua publicação. Junto aqui, tomo também reflexões trazidas a partir de seu texto intitulado: Inconveniências do corpo como resistência (2019).

O projeto mercantil eurocêntrico nos legou a "Colonialidade", a qual Mignolo na esteira do sociólogo peruano Anibal Quijano aponta que: “equivale a uma matriz ou padrão colonial de poder, o qual ou a qual é um complexo de relações que se esconde detrás da retórica da modernidade (o relato da salvação, progresso e felicidade) que justifica a violência da colonialidade" (MIGNOLO. 2017, p. 13). Este poder representado na América Latina por nações colonizadoras: Espanha, Portugal, França, Inglaterra e mais a frente pelos EUA.

A produção de conhecimento pautado pela modernidade/colonialidade se fez hegemônico desconsiderando qualquer pensar que não fosse o europeu, o eurocentrismo foi basilar para o colonialismo e seus empreendimentos mercantilista bem como para o próprio sistema capitalista. O projeto racional cartesiano com sua visão de mundo a partir do solo europeu, faz daqueles que se encontram fora dos seus perímetros apenas sujeitos objetos. Assim, as práticas as quais se valeram para escravizar, saquear, e dizimar povos mundo a fora, são justificadas por eles. Penso aqui, o eurocentrismo na esteira de Mignolo e apoiando-se em Quijano: 
Eurocentrismo é, aqui, o nome de uma perspectiva de conhecimento cuja elaboração sistemática começou na Europa Ocidental antes de mediados do século XVII, ainda que algumas de suas raízes são sem dúvida mais velhas, ou mesmo antigas, e que nos séculos seguintes se tornou mundialmente hegemônica percorrendo o mesmo fluxo do domínio da Europa burguesa. (QUIJANO. 2005. p. 126)

O pensamento moderno colonialista teve no eurocentrismo um grande pilar, para assim impor o projeto hegemônico com o uso da teologia cristã e do cientificismo cartesiano. Darcy Ribeiro aponta três heranças eurocêntrica para a América Latina, sendo a primeira o racismo que, em suas palavras, é a "arma principal do arsenal ideológico europeu de dominação colonial" (RIBEIRO. 2017, p. 84). A segunda herança diz respeito a superioridade que o europeu considerava ter, algo já descrito neste trabalho, mas que por anos implicou numa visão de mundo que desconsiderava qualquer cultura e/ou saber fora de seus perímetros. A terceira herança apontada por Ribeiro diz respeito a expansão da cristandade, em sua face salvacionista, tanto na vertente católica como na protestante, "cristianizar significou sempre subjugar povos a ferro e fogo." (RIBEIRO. 2017, p. 85). Por meio da razão moderna/colonial, o pensamento eurocêntrico empreendeu uma política etnocêntrica, apoiada na ideia de sua superioridade quanto civilização, única detentora do saber. O que Mignolo, com base em Quijano, aponta como constituição da ideia de modernidade que se ligou a epistemologia e à colonialidade do poder, o que dessa maneira, desqualificando qualquer sociedade e de povos que não fossem europeus cristãos e assim ocidentais.

Propor que se pense criticamente na produção do saber, descolonizando assim o fazer científico, as pesquisas acadêmicas, é caminhar em direção do fomento de diálogos com saberes tradicionais e periféricos, e desse modo propiciar à escuta das vozes dos pensamentos subalternos, num espaço que historicamente seguiu a premissa moderna de só enxergar o saber na razão cientifica, adotando uma superioridade e se fechando assim entre seus "iguais". Mignolo aponta que: "a produção do conhecimento é inseparável das sensibilidades do local geoistórico e que os locais históricos, no mundo colonial/moderno, foram moldados pela colonialidade do poder." (MIGNOLO. 2003, p. 249), ao propor aqui um pensamento outro, na trilha do teórico argentino, para erigir pesquisas numa visada descolonial, deve-se levar em conta "as marcas inscritas em seus corpos pela colonialidade do poder." (MIGNOLO. 2003, p. 249). Reconhecer as premissas do projeto moderno/ocidentalista é o primeiro passo para se buscar descolonizar a maneira de pensar moderna, e assim valorizar saberes outros, ou seja, aquilo que o pensamento hegemônico desconsiderou e tentou tornar invisível.

Penso ser oportuno trazer Silviano Santiago para este diálogo, visto que muitas de suas elucubrações apontam para uma visada pós-colonial, tanto em suas reflexões a respeito da literatura latino-americana, quanto do próprio papel do crítico e dos intelectuais latinos, 
poderia até ir mais além pois o autor mineiro deixa nítido a caracterização de suas ficções como suplemento de suas teorizações críticas, algo próprio de seu estilo, que eu tenho lido como o seu bios professoral. A respeito do perfil anticolonialista que o mineiro demonstra em vários de seus ensaios como aponta este trecho: A colonização pela propagação da Fé e do Império é a negação dos valores do Outro
(Camões infelizmente não foi bastante lúcido para perceber que a moeda tem duas
faces). A tripla negação do Outro para ser mais preciso. Primeiro: do ponto de vista
social, já que o indígena perde a liberdade, passando a ser súdito de uma coroa
européia. Segundo: o indígena é obrigado a abandonar o seu sistema religioso (e
tudo o que ele implica de econômico, social e político), transformando-se - pela
força da catequese -em mera cópia do europeu. Terceiro: perde ainda sua identidade
linguística, passando gradativamente a se expressar por uma língua que não é a sua.
(SANTIAGO. 2002, p. 225)

Santiago como é possível ler nessa citação, não se omite em arrolar sua leitura sobre o colonialismo e seus violentos efeitos, mesmo não sendo um crítico descolonial, traz em sua leitura uma visada que não obedece ao cânone, ou mesmo as teorias modernas eurocentradas, teimando em aceitar a superioridade dos teóricos europeus o autor mineiro "desloca o pensamento destes autores para fora do cânone moderno e os faz vivos, atuantes, políticos" (LOPES. 2012, p. 26), em nítida característica de superação da ideia de que o pensamento moderno/ocidental é hegemônico e único a ser validado teoricamente. Numa típica opção que possibilita que eu enxergue nesta característica, uma típica mostra de desobediência epistêmica demonstrando como o europeu que chegou ao novo continente traz consigo a sede mercantil e a cruz, adotando a premissa de que aqueles que habitavam povoados e tribos fora dos perímetros europeus, deveriam ser considerados por eles (europeus), como povos selvagens sem fé, lei ou rei. De maneira que não respeitavam assim os costumes, a cultura e a forma de vida que os povos não europeus levavam, o que Mignolo aponta quando escreve que estes corpos "habitam memórias diferentes, e, sobretudo, diferentes concepções e 'sensibilidade' de mundo." (MIGNOLO. 2017, p. 20), e que o europeu com sua "visão de mundo" não só desvaloriza como desconsidera.

Insiro-me também nessa reflexão na condição de pesquisador acadêmico, que pensa e habita este lócus fronteiriço, que vive imerso nesta paisagem biogeográfica da fronteira-Sul, sendo envolvido por sensibilidades que afloram neste lócus e que apre(e)nde a partir/com as histórias e sensibilidades locais. Mais ainda, como um homem negro que busca reexistir de maneira outra, frente a um quadro de racismo estrutural, que gera estatísticas brutais no que tange à vida de homens e mulheres de pele preta. Pensando minha condição e de demais habitantes deste lócus como corpos inconvenientes que resistem politicamente (SANTIAGO, 
2019) frente ao que o projeto moderno/colonial/ocidentalista erigiu como norma a ser seguida, como uma boa conduta.

Deste local concreto onde sujeitos subalternizados se levantam buscando reexistir frente as agruras suscitadas pelo projeto moderno, colonialista, capitalista, branco-héteropatriarcal-falocêntrico. Se configurando como transgressores às imposições do padrão, imposto como norma, ao longo do desenvolvimento desse projeto moderno. Essas vozes são desvalorizadas como ao longo da história foram notavelmente invisibilizadas, desconsideradas quanto sua capacidade de produzir reflexões epistemológicas. Para os ouvidos eurocentrados pensamentos e teorizações erigidos desses corpos latino-americanos são apenas balbucios inconsistentes, o que levou a o teórico uruguaio Hugo Achugar a questionar:

[..] para os ouvidos do hemisfério norte é sempre o do "balbucio" e da incoerência ou da inconsistência teórica? Não será que o "balbucio teórico latino-americano" não é incoerência nem inconsistência? Não será que esse balbucio teórico é outro pensamento ou um pensamento outro? Não será que balbuciar é um "discurso raro", um "discurso orgulhosamente balbuciante"? Não será que eu tenha escolhido "balbuciar teoricamente" como um modo de marcar e prestigiar meu discurso? (ACHUGAR, 2006, p. 35).

Tendo como reflexão os questionamentos de Achugar a partir dessa citação, fica nítida a desvalorização do pensamento não ocidental, de maneira que o teórico uruguaio aponta a metáfora do balbucio para demonstrar como "os ouvidos do hemisfério norte" desdenham dos discurso latino-americano. Tal apontamento ressalta o que tenho descrito como invisibilização de corpos subalternizados, num sentido que engloba, filosofia e cultura histórica destes corpos. O que o processo de colonização buscou fazer, em nome do que chamou de salvamento das almas selvagens e barbaras, daqueles corpos não europeus/católicos.

Entendo como necessário ter em mente que "a produção do conhecimento é inseparável das sensibilidades do local geoistórico e que os locais históricos, no mundo colonial/moderno, foram moldados pela colonialidade do poder” (MIGNOLO. 2003, p. 249). Desta forma vejo que "o sujeito social pensa, ou produz conhecimento, a partir de sua "história local", ou seja, a partir do modo que "lê" ou "vive" a "história local" (ACHUGAR, 2006, p. 29), de modo que, assumo como condição para este intento a opção descolonial, superando o que é tido apenas como balbucio, convicto de que esta opção "não é só uma opção de conhecimento, uma opção acadêmica, um domínio de 'estudo', mas uma opção de vida, de pensar e de fazer" (MIGNOLO, 2017, p. 31). Tendo como basilar para essa opção assumida, que ela requer a adoção de uma perspectiva que tem como base a desobediência epistêmica. A qual vemos no apontamento do teórico argentino: 
[...] toda mudança de descolonização política (não-racistas, não heterossexualmente patriarcal) deve suscitar uma desobediência política e epistêmica. A desobediência civil pregada por Mahatma Ghandi e Martin Luther King Jr. foram de fato grandes mudanças, porém, a desobediência civil sem desobediência epistêmica permanecerá presa em jogos controlados pela teoria política e pela economia política eurocêntrica. (MIGNOLO, 2008, p. 287).

Penso que para o intento aqui exposto, de alcançar este olhar outro, é auspicioso pensar a partir da crítica biográfica fronteiriça, pois ela impele a um pensar e um fazer, pautado na desobediência epistêmica, que a guisa da citação de Mignolo, deve além de se pautar por uma desobediência civil buscar construir uma pratica epistemológica outra, não tentando apagar o que existe como padrão de pensamento teórico. De forma que se torna primordial, superar esse padrão hegemônico, transgredir assim a imposição de reiterar disciplinarmente o que é imposto como forma única de se pensar epistemologicamente, e desta maneira romper com as agruras que esse padrão provoca. Para que assim dar voz e valor aos corpos invisibilizados pelo pensamento moderno/colonial.

A partir da realidade que emerge sensibilidades geoistoricas deste lócus onde se pensa e vive arrolando reflexões conceituais relacionadas à arte, cultura, ao saber, em paisagens/sujeitos biogeográficos. Numa reflexão que está diretamente relacionada ao meu bios e meu lócus, e que por meio da articulação com algumas imagens, que arrolo a posteriori nesse texto, intentando ao exercício teórico de aprender a desaprender para reaprender (MIGNOLO, 2008). Penso a condição dos corpos marginalizados pela colonialidade/modernidade, bem como seus discursos (balbucios) que são erigidos em resistência política, numa luta para se (re)existirem como seres pensantes, a partir de meu lócus: a fronteira-Sul, de modo que só posso alçar tal reflexão me pautando nos estudos descoloniais.

\subsection{Discurso transgressor latino-americano e a desobediência epistêmica}

\footnotetext{
Daqui em diante, a opção descolonial não é só uma opção de conhecimento, uma opção acadêmica, um domínio de 'estudo', mas uma opção de vida, de pensar e de fazer. Ou seja, de viver e con-viver com quem acha que a opção decolonial é a sua e com quem tem encontrado opções paralelas e complementares à descolonial. MIGNOLO, 2017, p. 31
}

Ao me propor pensar numa opção descolonial não há como desprezar minha condição, primeira de estudante/pesquisador que se encontra na fronteira sul, no estado de Mato Grosso do Sul, que faz fronteira com Bolívia e Paraguai. Segunda, minha própria (afro)descendência, e por sentir cotidianamente aquilo que o pensamento moderno, colonialista e imperialista legou a quem tem a pele preta como eu. Terceira questão, diz respeito ao fato de eu ter 
nascido no começo da década de 80 . Vi ainda na infância a abertura para democracia após as terríveis décadas onde imperou o sistema ditatorial militar no Brasil, a exemplo de outros países latino-americanos.

Em 1981, ano de meu nascimento, erguiam-se os gritos pelas diretas já! Movimento que ganhou este nome por requerer eleições diretas para presidente. Vozes que foram por anos abafadas se uniam nas grandes cidades e já não eram contidas pelo aparelho bélico militar estatal. Este cenário, o mesmo em que Silviano Santiago encontra quando escreve sua ficção Em Liberdade, que por coincidência é publicado neste mesmo ano de 1981. Santiago trabalha nesta ficção, bem como em suas demais ficções, vários aspectos da teoria literária, mas também faz uso de seu cabedal teórico para tratar politicamente. Em Liberdade, é um exemplo disto, nele o mineiro descreve por meio de uma digressão temporal a realização de uma missa pela morte do poeta e rebelde do século XVIII Cláudio Manuel da Costa, remetendo a morte similar sofrida pelo jornalista Wladimir Herzog na década de 1970. Fazendo uma crítica política a repressão estatal.

Pensando essa condição do papel do intelectual evocado por Silviano Santiago, ao longo desses 40 anos que no país e em grande parte do continente latino americano deu-se o crescimento de democracias e ascensão de partidos e movimento progressistas, fica nítido que o papel do intelectual é hoje ainda mais destacado, visto que o desenvolvimento do capitalismo de mercado cooptou inúmeros produtores culturais, artistas, escritores e intelectuais. Mesmo quando olhamos para dentro do mundo acadêmico vemos que o cenário não se diferencia muito, a onda liberal espalhada pelo mundo a fora manteve aberta feridas coloniais que ficaram ainda mais expostas. O racismo estrutural e os inúmeros casos de violência contra pessoas negras, um quadro que demonstra tratar-se de um genocídio de pessoas de pele preta, evidencia como uma necropolitica impera no continente latino americano. E as vozes que se fazem dissidentes tornam esses atores como corpos inconvenientes, numa performance transgressora e marginalizada, demostrando como casos como do musico Evaldo Rosa assassinado em uma operação da polícia militar na cidade do Rio de Janeiro em abril do ano de 2019, que foi justificado pela corporação de polícia como um caso em que o musico fora confundido com um bandido procurado, o que ressalta assim como "80 tiros te lembram que existe pele alva e pele alvo" (EMICIDA, 2019, s/p).

O movimento rap, a poesia de rua, a chamada cultura marginal, são hoje junto sobretudo ao movimento feminista negro destacado detentores desse discurso transgressor que reforça nossa reflexão de nosso próprio papel de pesquisadores e atores dos espaços acadêmicos que também podem transgredir e assim descolonizar nosso fazer acadêmico, 
desobedecendo epistemologicamente, numa opção descolonial, adotando a desobediência ao que é imposto pelo pensamento moderno/ocidental como único modo de pensar cientifica e filosoficamente, e assim pensando este corpo racializado, invisibilidade e silenciado na fronteira (subalternidade), que ousa desobedecer às normas instituídas, corpo que se faz inconveniente para o pensamento moderno.

A exclusão vista nas favelas das grandes cidades da latino-americanas, como na Villa 31 e no Fuerte Apache na cidade de Buenos Aires, em Buenaventura, ou outras cidades em todo o departamento Chocó na Colômbia. Ou ainda nas comunidades e morros de São Paulo, Belo Horizonte, Rio de Janeiro entre outras cidades brasileiras como Campo Grande - MS onde vivo. Também em outros países da América Latina podem ser vistos os mesmos problemas de exclusão e tudo o que acarretam, como violência e falta de infraestrutura básica. Quadro que me faz lembrar das músicas do grupo oriundo do departamento colombiano de Chocó, ChocQuibTown, ou do grupo paulista de Rap, o Racionais MC's, que, fazendo uso de suas canções e expressões artísticas, expõe a situação cotidiana vivida em seus redutos. $\mathrm{O}$ trecho a seguir é retirado da letra da canção de título "Negro drama", do grupo Racionais MC's:

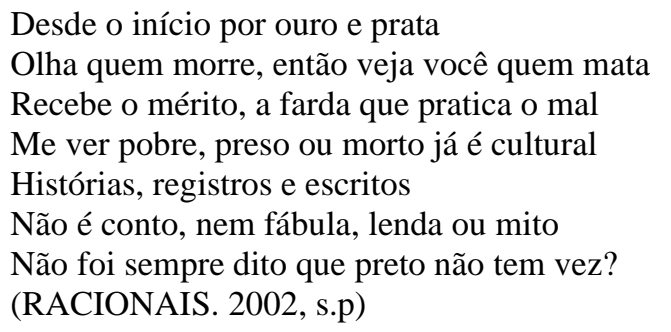

As grandes aglomerações habitacionais vistas nas grandes cidades latino-americanas são consequências de anos de políticas que vilipendiaram a população pobre sobretudo a população afrodescendente e ameríndia. As expressões artísticas marginais como movimento hip hop, com seus grafites, raps e slam's, formam as vozes que cotidianamente reverberam os problemas e o caos existente nestas localidades, de maneira que ao transgredirem por meio de seus discursos acabam se tronando inconvenientes frente a sociedade e o Estado que mantém esse quadro de caos e exclusão. Nesse sentido é impar os apontamentos de Silviano Santiago a partir da figura do artista, que tem uma postura de transgressão frente a liberdade que lhe é reprimida, Silviano Santiago aponta os corpos em cena, dos artistas da banda Secos e Molhados sobretudo de Ney Matogrosso.

A transformação na performance do corpo dos cantores se dá, repito, em cena aberta. Ocorre durante o show ao vivo, ou televisionado ou, ainda, gravado em vídeo comercial. Por isso, a imagem inconveniente do corpo do cantor extrapola os limites estreitos do palco e da sala de espetáculos e vai além - se transmitida ou, 
posteriormente, reproduzida - dos limites da telinha e do ambiente doméstico. (SANTIAGO, 2019, s./p)

O escritor mineiro aponta: "foco o momento em que, no palco, o corpo do cantor torna-se inconveniente. É mutante e significa" (SANTIAGO, 2019, s./p). Com base nos apontamentos dos estudos descoloniais, penso ser relevante refletir na esteira de Santiago, no contexto em que vivo e busco por um pensamento outro, a imagem do corpo inconveniente que o vídeo clipe da canção que tem como título "AmarElo", do artista paulistano, Leandro Roque Oliveira mais conhecido como Emicida, essa canção trata da luta, de força e diversidade, e para interpretá-la juntam-se a voz do cantor Emicida, também a cantora nãobinária Majur e a cantora drag queen Pabllo Vittar. Ao se observar as cenas do vídeo clipe gravadas no Complexo do Alemão, no Rio de Janeiro que ilustram a letra que impele a reflexão político social da situação de exclusão que as minorias se encontram, a qual Emicida explica que aproxima a causa negra e a causa LGBT. "Não dá pra lutar pela liberdade pela metade, ainda mais hoje. Em momento nenhum a letra faz referência à política, mas não tem como não pensar no Brasil de 2019." (EMICIDA. 2019, s./p). O trecho da letra de "AmarElo" reproduzido a seguir denota o que o autor descreveu.

\footnotetext{
Permita que eu fale, não as minhas cicatrizes

Elas são coadjuvantes, não, melhor, figurantes, que nem devia 'tá aqui

Permita que eu fale, não as minhas cicatrizes

Tanta dor rouba nossa voz, sabe o que resta de nóiz?

Alvos passeando por aí

Permita que eu fale, não as minhas cicatrizes

Se isso é sobre vivência, me resumir a sobrevivência

É roubar o pouco de bom que vivi

Por fim, permita que eu fale, não as minhas cicatrizes

Achar que essas mazelas me definem, é o pior dos crimes

É dar o troféu pro nosso algoz e fazer nóiz sumir.

(EMICIDA, BELCHIOR, BALBINO, VASSAO. 2019, s./p)
}

Os corpos inconvenientes como dos artistas da canção AmarElo, que com suas vozes e suas performances, acabam por transgredir o decoro instituído por grande parte da sociedade brasileira, e que tem eco no discurso conservador do atual presidente brasileiro. As histórias locais brasileiras se forjaram de lutas e resistências, por vezes resistências às imposições governamentais, às vezes resistências a mudanças progressistas e que visam maior igualdade e justiça social, as forças conservadoras têm buscado ao longo desta história permanecer dentro da lógica pautada pelo projeto da modernidade colonialista. Para superação desta lógica, que além de ter por anos causado um quadro de exclusão social, preconceito racial, e políticas etnocêntricas, urge que este pensamento outro seja constante em nossas pesquisas e diálogos acadêmicos. De tal forma que assim valorize os saberes, para além da razão 
ocidental, nas vozes, nos discursos, que ousam ser dissonantes e nas performances de corpos inconvenientes, de artistas, políticos e pesquisadores.

\section{Conclusões}

Ao voltar o olhar para a própria realidade latino-americana, mesmo para a nossa realidade nacional, ficam caracterizados também, centros hegemônicos que reproduzem exclusões e divide em centros e periferia, estando à região de onde pensamos e teorizamos relegada a periferia brasileira, na fronteira sul com Bolívia e Paraguai, deste local periférico e fronteiriço devemos a esteira das teorizações de Nolasco, apreendermos e replicarmos em nosso fazer acadêmico, a consciência descolonial e a desobediência epistêmica, como conceitos basilares, pois mesmo com os avanços dos estudos pós-coloniais ainda é notório o fato de que o discurso moderno ainda impera em boa parte da academia.

Inferindo ainda minha condição, onde meu corpo, que ousa re-existir, quando as estatísticas apontam para uma vida relativamente curta, com um nível escolar baixo, eu sou o homem preto que nasceu, cresceu e ainda vive na periferia de um centro urbano, em meio à violência e o medo, de criminosos e mesmo da violência policial. $\mathrm{O}$ homem preto da periferia que ousa, contrariando as estatísticas, a sobreviver, pensar, pesquisar e a escrever, um corpo que desobedece epistemologicamente, que escre(vi)ve na e a partir da minha fronteira-Sul um lugar de "exposição de exterioridades biogeográficas como modos de produção de arte, cultura e conhecimentos. Um lugar em que o corpo físico como compreendemos hoje especialmente nas artes - está cada vez mais no lugar moderno do corpo padronizado" (BESSA-OLIVEIRA. 2019, p. 94).

Portanto penso que só com uma prática descolonizante em nossas abordagens, sobretudo acadêmicas pautados numa desobediência epistêmica em nossas vivencias pedagógicas, críticas e em nossas pesquisas será possível estabelecer um olhar outro. Como corpos inconvenientes que ousam resistir e nadar contracorrente política e artisticamente para assim superar o pensamento ocidentalista eurocêntrico pautado pela visão de mundo trazido pelo pensamento da modernidade.

\section{Referências}

ACHUGAR, Hugo. Planetas sem boca: escritos efêmeros sobre arte, cultura e literatura. Tradução: Lyslei Nascimento. Belo Horizonte. Editora UFMG, 2006

BESSA-OLIVEIRA, Marcos Antônio. Pedagogias da diversalidade. In: CADERNOS DE ESTUDOS CULTURAIS: Pedagogias Descoloniais, Pedagogias, v. 1 n. 21 (2019). 
Disponível em: https://periodicos.ufms.br/index.php/cadec/article/view/9691 Acesso em: nov. 2020.

EMICIDA, Leandro Roque de Oliveira, Letra de Ismália, (C) Warner Chappell Music 2019. São Paulo. Disponível em: https://www.letras.mus.br/emicida/ismalia-part-larissa-luz-efernanda-montenegro/ Acesso em: nove. 2020

EMICIDA, Leandro Roque de Oliveira, VASSÃO, Felipe; BELCHIOR, Antonio Carlos; BALBINO, Eduardo Dos Santos. Letra de AmarElo (C) Laboratorio Fantasma Producoes Ltda Me 2019. São Paulo. Disponível em: https://www.musixmatch.com/pt-br/letras/Emicida-featMajur-Pabllo-Vittar/AmarElo. Acesso em: nove. 2020

EMICIDA, Leandro Roque de Oliveira. Emicida aproxima causas negra e LGBTQ+ em clipe com Pabllo Vittar e Majur. Portal iG São Paulo 2019. São Paulo. Disponível em: https://gente.ig.com.br/cultura/2019-06-25/emicida-aproxima-causas-negra-e-lgbtq+-emclipe-com-pabllo-vittar-e-majur.html. Acesso em: nove. 2020

LOPES, Denilson. Do entre-lugar ao transcultural. In: LOPES, Denilson. No coração do mundo. Rio de Janeiro: Rocco, 2012, p. 21-46.

MIGNOLO. Walter. Histórias locais/Projetos globais. Trad. de Solange Ribeiro de Oliveira. Belo horizonte: Editora UFMG, 2003, 1. ed. rev.

MIGNOLO, Walter. Desafios decoloniais hoje. In: Revistas UNILA: Epistemologias do Sul, Foz do Iguaçu-PR, 2017. Disponível em:

https://revistas.unila.edu.br/epistemologiasdosul/article/download/772/645 Acesso em: out. 2020.

MIGNOLO, Walter. Desobediência epistêmica: a opção descolonial e o significado de identidade em política. 2008. Disponível em:

http://professor.ufop.br/sites/default/files/tatiana/files/desobediencia_epistemica_mignolo.pdf. Acesso em: dez. 2020.

NOLASCO, Edgar Cézar. Perto do coração selbaje da crítica fronteriza. São Carlos: Pedro\&João Editores, 2013.

NOLASCO, Edgar Cézar. Silviano Santiago e o lugar onde o sol se põe: entrelugares epistemológicos ao sul da fronteira-sul. In: CADERNOS DE ESTUDOS CULTURAIS:

Silviano Santiago: uma homenagem. v. 6, n. 11. Campo Grande: Editora UFMS, 2014, p. 1729.

QUIJANO, Anibal. Colonialidade do poder, Eurocentrismo e América Latina. In: A colonialidade do saber: eurocentrismo e ciências sociais. Perspectivas latino-americanas. Buenos Aires. Biblioteca virtual CLACSO, 2005. Disponível em: http://biblioteca.clacso.edu.ar/clacso/sur-sur/20100624103322/12_Quijano.pdf Acesso: nov. 2020.

RIBEIRO, Darcy. América Latina: a pátria grande. $3^{\text {a }}$ edição. São Paulo. Global, 2017. 
RACIONAIS, MC's. Negro Drama. São Paulo, 2002. Disponível em: https://www.musixmatch.com/pt-br/letras/Racionais-MC-s-3/Negro-Drama Acesso: dez. 2020.

SANTIAGO, Silviano. Em liberdade: uma ficção de Silviano Santiago. $5^{\mathrm{a}}$ edição. Rio de Janeiro, Rocco, 1994.

SANTIAGO, Silviano. Nas malhas da letra: ensaios. Rio de Janeiro, Rocco, 2002.

SANTIAGO, Silviano. O entre-lugar do discurso latino-americano. In: Uma literatura nos trópicos: edição ampliada. Recife: Cepe, 2019, p. 09-30.

SANTIAGO, Silviano. Inconveniências do corpo como resistência política. 2019. Disponível em: https://issuu.com/suplementopernambuco/docs/pe_165_web. Acesso: dez. 2020. 